\title{
ASPECTOS RELEVANTES DA JOINT VENTURE NACIONAL E INTERNACIONAL
}

\section{RELEVANT ASPECTS OF NATIONAL AND INTERNATIONAL JOINT VENTURES}

\author{
Miguel Ângelo Marques ${ }^{1}$
}

\begin{abstract}
RESUMO
Em um mundo cada vez mais globalizado, a possibilidade de o empresário desenvolver projetos específicos com a cooperação de parceiros locais é um grande diferencial. É nesse contexto que se insere a joint venture. O presente artigo tem por escopo abordar alguns aspectos dessa forma de investimento estrangeiro direto. Por se tratar de um estudo descritivo e exploratório, foi realizado com base na pesquisa bibliográfica e histórica, utilizando-se do método indutivo.
\end{abstract}

Palavras-chave: Globalização. Joint venture. Direito internacional privado. Investimento estrangeiro.

\section{ABSTRACT}

In an increasingly globalised world, the possibility for an entrepreneur to develop specific projects in cooperation with local partners is a major advantage. Joint ventures are part of this process. This article aims to address some aspects of this form of foreign direct investment. Since this is a descriptive and exploratory study, it has been performed on the basis of historical and bibliographical research and using the inductive method.

Keywords: Globalization. Joint venture. Private international law. Foreign investment.

\section{CONSIDERAÇÕES INICIAIS}

A empresa estrangeira que pretender ingressar no Brasil poderá lançar mão, entre outras possibilidades, do processo de nacionalização ou instalação de filial, agência, sucursal ou estabelecimento no País. Nesse caso, deverá observar o disposto na instrução normativa do Departamento de Registro Empresarial e

\footnotetext{
${ }^{1}$ Doutorando e Mestre em Direito Internacional pela Pontifícia Universidade Católica de São Paulo - PUC/SP e Professor Universitário na Cidade de São Paulo, onde leciona as disciplinas de Direito Internacional Público, Direito Internacional Privado e Direitos Fundamentais.
} 
Integração (DREI) ํo 7, de 5 de dezembro de 2013 (alterada pela Instrução Normativa DREI nำ25, de 10 de setembro de 2014) ${ }^{2}$.

Como alternativa a esse processo longo e burocratizado, a sociedade estrangeira poderá optar pelas joint ventures, que representam, em síntese, uma associação entre empresas ou pessoas com o fim de criar ou desenvolver um empreendimento comum.

A joint venture nada mais é do que uma cooperação entre empresas ou pessoas que pode ou não assumir forma societária. Segundo esta forma de investimento, se societária, o investidor estrangeiro poderá localizar um parceiro em nosso país e investir na qualidade de sócio, em sua sociedade. Desta forma a totalidade do capital social não será do investidor estrangeiro. (FINKELSTEIN, 2008, p. 257-258).

Esse mecanismo, além de se apresentar como uma alternativa interessante à burocracia estatal, já que permite a atuação de sociedades estrangeiras no território nacional por meio da cooperação de empresas locais, possibilita também uma redução nos custos e riscos empresariais, na medida em que facilita a distribuição e a comercialização dos bens de produção.

\footnotetext{
${ }^{2}$ De acordo a Instrução normativa DREI № 7/13, a sociedade estrangeira interessada deverá solicitar autorização do governo federal para instalação e funcionamento, em requerimento dirigido ao Ministro de Estado Chefe da Secretaria da Micro e Pequena Empresa da Presidência da República, protocolizado no Departamento de Registro Empresarial e Integração - DREI, que o examinará sem prejuízo da competência de outros órgãos federais.A empresa autorizada a funcionar no país poderá, mediante autorização do governo federal, nacionalizar-se, transferindo sua sede para o Brasil, devendo, para esse fim, apresentar os seguintes documentos: I - requerimento ao Ministro de Estado Chefe da Secretaria da Micro e Pequena Empresa da Presidência da República, protocolizado no Departamento de Registro Empresarial e Integração; II - ato de deliberação sobre a nacionalização; III - estatuto social ou contrato social, conforme o caso, elaborados em obediência à lei brasileira; IV prova da realização do capital, na forma declarada no contrato ou estatuto; $V$ - declaração do representante no Brasil de que aceita as condições em que for dada a autorização de nacionalização pelo Governo Federal; e VI - guia de recolhimento do preço do serviço. Após a expedição do decreto de nacionalização caberá à sociedade empresária arquivar na junta comercial da unidade federativa onde se localizará a sua sede, a folha do Diário Oficial da União que publicou o respectivo decreto e os atos a que aludem os incisos II a V do artigo anterior, sem prejuízo da apresentação dos documentos que instruem, obrigatoriamente, os pedidos de arquivamento de sociedades empresárias brasileiras. Existindo filiais, sucursais, agências ou estabelecimentos em outras unidades federativas, deverá a sociedade empresária nacionalizada proceder ao arquivamento, nas respectivas Juntas Comerciais, de certidão simplificada fornecida pela Junta Comercial da sua sede.
} 


\section{ORIGEM}

Como um típico instituto de direito mercantil as joint ventures resultam de práticas reiteradas que, de forma gradual e crescente, passaram a receber regulamentação específica.

Tradicionalmente, no direito inglês, a joint venture tinha conotação de aventura conjunta, ligada a um contrato de direito de navegação, visando auferir lucros com um negócio ultramarino, de exportação/importação. No entanto há que se notar que a lei inglesa nunca concebeu a joint venture como figura autônoma, própria, assumindo essa um caráter pessoal, sendo referida como particularized partneship ou, ainda, special partnership.

No final do século XIX, as joint ventures foram sendo constituídas, em regra geral, sob a forma societária, dentro ainda do setor ferroviário, e com os objetivos de construir estações em comum, bem como de adquirir carruagens para a utilização nas linhas.

Já no século XX são largamente constituídas joint ventures na indústria petrolífera, tendo como objetivo particular a pesquisa e o desenvolvimento conjunto. Essa tendência de concentração dos recursos estende-se, posteriormente, à indústria do aço, constituindo importante fator de desenvolvimento do setor. (MIRANDA; MALUF, 2009, p. 1-10).

Entre a segunda metade do século $X I X^{3}$ e o início do século $X X$ passam a ser reconhecidas pelos tribunais norte-americanos ${ }^{4}$, atingindo, posteriormente, a universalidade de seu uso nos negócios internacionais (BAPTISTA; DURANDBARTHEZ, 1991, p. 3 apud BASSO, 2002, p. 102).

As joint ventures têm origem na prática privada, nos contratos que as constituem e nas operações comerciais, não sendo criação dos legisladores nacionais (BASSO, 2002, p. 15).

\footnotetext{
3 "A joint venture não representa um fenômeno novo na prática norte-americana. Historicamente, como bem determina Bonvicini, um dos primeiros casos de empresa conjunta data da segunda metade do século XIX, quando da criação da Terminal Railroad Association of St. Louis (1889), constituída por 15 companhias ferroviárias, com o objetivo de aparelhar importante malha ferroviária." (FERRAZ, 2001. p. 109).

${ }^{4}$ Precedentes citados por Carlos Maria Gambaro (2000, p. 64): 'Bruce v. Hastings', vt. 380 (1868); 'Ross v. Willet', 27 N.Y., Supp., 785,786 (Ist. Dept. 1895); 'Lobsitz v. E.Lissberger Co.', 156 N.Y., Supp. 556 (Ist. Dept. (1915); 'Reid v. Shaffer', 196 N.Y. Supp. 553, 561 (6th Cir. 1918); 'Columbian Laundry v. Henken', 196 N.Y. Supp. 523, 525 (1st Dept. 1922); 'Finney v. Terrel', 276 S.W. 340 (Tex. Civ. App., 1925)".
} 
No Brasil, a utilização do instituto começa a ser percebida no final do Século $X X$, quando ocorre a abertura da economia.

No meio desse processo de globalização, as joint ventures se apresentam como uma alternativa interessante às necessidades de um mercado cada vez mais exigente e globalizado, que possibilita a troca de conhecimento técnico, além de poder ser aplicada nos mais diversos ramos de atividade, como, v.g., projetos industriais, execuções de obras, pesquisas e desenvolvimentos, atividades financeiras e prestação de serviços.

\section{CONCEITO}

Ainda hoje não existe uma definição legal clara para o instituto, razão por que colacionamos abaixo algumas definições doutrinárias:

Ronald Charles Wolf (2002, p. 6) entende que a joint venture seria "a particular form of doing business by one party in a jurisdiction, either foreign or domestic, by means of a stable, permanent legal entity with another party, for a term, usually indefinite, with economic independence and a lawful commercial purpose."

José Maria Rossani Garcez (1999, p. 214) assevera que se trata de uma forma de associação ou método de cooperação entre empresas independentes, que resolvem atingir um determinado objetivo, a venture, o negócio especulativo ou a aventura em comum aglutinando seus esforços, capitais, experiência e tecnologia.

Segundo Maristela Basso (2002, p. 39), a joint venture corresponde a uma forma ou método de cooperação entre empresas independentes, denominado em outros países de sociedade de sociedades, filial comum, associação de empresas etc.

Miguel Reale (1994, p.131), por sua vez, assegura que a joint venture pode ser entendida de maneira genérica, como o faz o Dicionário Jurídico da Academia Brasileira de Letras Jurídicas, nos seguintes termos: "associações para um determinado empreendimento mercantil ou industrial, por cujos investimentos se

\footnotetext{
5 "Uma maneira específica de se realizar negócios em uma jurisdição, sendo estrangeira ou nacional, formando uma entidade estável e permanente com outro interessado, por meio de um contrato, normalmente por tempo indeterminado, com independência econômica e uma intenção dentro da legalidade." (WOLF, 2002, p.6, tradução nossa).
} 
obrigam e ou de cujos resultados fruem os seus participantes, dentro do plano assentado em contrato".

Eduardo Spinola Castro (2005, p. 124-145), por seu turno, entende que a expressão joint venture designa, genericamente, a cooperação estável entre sociedades para o desenvolvimento de um ou mais empreendimentos comuns.

Bulhões Pedreira (1992), por fim, define joint venture como o contrato de sociedade entre dois empresários, que se obrigam a conjugar esforços e recursos com o fim de exercer em conjunto a função empresarial em determinado empreendimento econômico, ou empresa."

A característica essencial da joint venture é a realização de um projeto comum, empreendimento, cuja duração pode ser curta ou longa, porém com prazo determinado (MIRANDA; MALUF, 2009, p. 1-10).

Depreende-se, portanto, que a joint venture "corresponde a uma forma ou método de cooperação entre empresas de um mesmo país ou de países diferentes, sendo usada na linguagem comercial para designar qualquer acordo empresarial para a realização de um projeto específico, uma aventura comum, independentemente da forma jurídica adotada." (BASSO, 2002, p. 15).

No campo do direito da concorrência, existe uma definição infralegal, estabelecida pela Resolução $\mathrm{n}^{\circ}$ 2, de 29 de maio de $2012^{7}$, que disciplina a notificação dos atos de que trata o artigo 88 da Lei n-12.529, de 30 de novembro de 2011:

Art. 8 São hipóteses enquadráveis no Procedimento Sumário, as seguintes operações:

I - Joint Ventures clássicas ou cooperativas: casos de associação de duas ou mais empresas separadas para a formação de nova empresa, sob controle comum, que visa única e exclusivamente à participação em um mercado cujos produtos/serviços não estejam horizontal ou verticalmente relacionados.

\footnotetext{
${ }^{6}$ Parecer publicado em Lei das S/A, 1. ed., 1. v., p. 363, Rio de Janeiro: Renovar, 1992 apud CASTRO, 2005.

${ }^{7}$ Publicada no Diário Oficial da União de 31 de maio de 2012, № 105, sessão 1, p. 88-91, alterada pela Resolução no 09, de 1ำ de outubro de 2014, publicada no Diário Oficial da União, de 07 de outubro de 2014, no 193, seção 1, p. 43-44.
} 
Para nós, essa figura jurídica originada da prática empresarial norteamericana e muito utilizada no comércio internacional, pode ser entendida como a forma pela qual empresas independentes se associam entre si com o escopo de desenvolver um empreendimento determinado e comum.

\section{CLASSIFICAÇÃO}

As joint ventures podem ser classificadas quanto à nacionalidade dos participantes (co-ventures), quanto à forma jurídica adotada, quanto ao risco do empreendimento e quanto à sua duração.

\subsection{Quanto à nacionalidade}

Quanto à nacionalidade, as joint ventures podem ser classificadas em nacionais e internacionais.

A joint venture nacional decorre da associação de duas ou mais empresas da mesma nacionalidade, enquanto na internacional, tomam parte no contrato de cooperação duas ou mais empresas de diferentes nacionalidades.

\subsubsection{Joint venture nacional}

No Brasil, nos termos do art. 11, caput, da Lei de Introdução às Normas do Direito Brasileiro, o critério utilizado para a caracterização da nacionalidade de uma empresa é o lugar da sua constituição.

Art. 11. As organizações destinadas a fins de interesse coletivo, como as sociedades e as fundações, obedecem à lei do Estado em que se constituírem.

De acordo com este critério:

[...] toda e qualquer empresa organizada em conformidade com as leis brasileiras e que tenha aqui sua sede e administração será considerada uma empresa brasileira, mesmo que a totalidade ou a maior parcela de seu capital tenha origem estrangeira. Empresa constituída ou registrada em território nacional e regida pelo nosso 
direito será sempre empresa brasileira. Contrario sensu, sociedade estrangeira será aquela constituída e organizada em conformidade com a legislação do país de origem, onde também mantém sua sede administrativa, ainda que no Brasil mantenha representação, subsidiária ou coligada. (FINKELSTEIN, 2009, p.108).

Como exemplo de joint venture nacional podemos citar a associação firmada pelas empresas Volkswagen e Ford na década de 1980, que resultou na criação da Autolatina. A ideia era potencializar os pontos fortes de cada empresa e compartilhar custos e riscos. Dessa união surgiram alguns modelos de veículos como: Versalles e Royale; Apollo e Verona, entre outros.

Em 2014, o Conselho Administrativo de Defesa Econômica (CADE) aprovou, sem restrições, um contrato de joint venture firmado entre o Banco do Brasil e a Cielo objetivando gerir negócios com cartões de crédito e de débito das duas instituições. De acordo com informações divulgadas pela imprensa ${ }^{8}$, o Banco do Brasil, em razão da operação, estimava um impacto financeiro da ordem de $R \$ 3,2$ bilhões no seu lucro líquido.

Em 2015, o Governo brasileiro, autorizou, sem restrições, um acordo do Santander Brasil (para criar uma joint venture) com a operação brasileira do banco da montadora francesa PSA Peugeot Citroën para oferecer produtos e serviços financeiros a consumidores e concessionários das marcas PSA no Brasil. Pelo acordo, o Santander Brasil vai deter 50 por cento do Banco PSA Finance Brasil e os $50 \%$ restantes ficarão com o Banque PSA. Por meio de controladas, o Santander Brasil também deterá 50 por cento das quotas da PSA Corretora de Seguros e Serviços e 100 por cento das ações da PSA Finance Arrendamento Mercantil ${ }^{9}$.

No início deste ano, o CADE admitiu a formação de outra importante joint venture. O caso envolveu a empresa (brasileira) Gerdau e as japonesas Sumitomo Corporation e Japan Steel Works (JSW). Segundo a imprensa ${ }^{10}$ a nova empresa envolverá $R \$ 280$ milhões em investimentos para a aquisição de novos equipamentos de produção.

\footnotetext{
8 Disponível em: <http://g1.globo.com/economia/negocios/noticia/2014/12/cade-aprova-joint-ventureentre-cielo-e-banco-do-brasil.html >. Acesso em: 7 abr. 2016.

9 Disponível em: <http://noticias.bol.uol.com.br/ultimas-noticias/economia/2015/09/30/cade-aprova-semrestricoes-joint-venture-do-santander-brasil-com-banco-psa.htm>. Acesso em: 7 abr. 2016.

${ }_{10}$ Disponível em: shttp://g1.globo.com/economia/negocios/noticia/2016/01/conselho-da-gerdau-aprovacriacao-de-joint-venture.html>. Acesso em: 7 abr. 2016.
} 


\title{
4.1.2 Joint venture internacional
}

$\mathrm{Na}$ international joint venture, a empresa estrangeira associa-se a uma empresa sediada no país onde pretende ver executado o seu projeto.

\begin{abstract}
A empresa estrangeira associa-se a uma empresa sediada no país em que a operação será executada, possibilitando que produtos ou serviços sejam inseridos em novos mercados com menores riscos, graças à possibilidade de associação com parceiros locais. Elas podem, ainda, levar tecnologia e marcas consagradas mundialmente, além de know-how para outros países. O parceiro local, geralmente, é aquele que possui conhecimento do mercado, das práticas comerciais e da conjuntura cultural e política regionais. Esta combinação, provavelmente, conferirá ao investidor estrangeiro maiores chances de crescimento e de sucesso efetivo. (AMARAL, 2004, p. 245-268).
\end{abstract}

Um caso que ilustra bem a aplicação de uma joint venture internacional ocorreu na década de 1970. Na ocasião, as empresas Chevron, Mobil, Gulf e a Petro-Canada (controlada pelo governo canadense), ligadas à indústria do petróleo, firmaram um contrato estimado inicialmente em 5,2 bilhões de dólares, para desenvolver e produzir petróleo no campo Hibernia. O local escolhido localiza-se a trezentos e quinze quilômetros da costa sudeste do Canadá; além de remoto, era extremamente perigoso, já que por ele passavam continuamente icebergs advindos de geleiras da Groenlândia.

Recentemente (dezembro de 2014), "os grupos aeroespaciais Airbus e Safran inauguraram formalmente uma joint venture para reunir suas atividades de lançadores espaciais, com o objetivo de garantir o futuro do foguete Ariane e cortar custos em face do lançamento do rival norte-americano SpaceX". Essa joint venture irá empregar 450 pessoas e será chamada Airbus Safran Launchers ${ }^{11}$.

\footnotetext{
11 Disponível em: <http://noticias.uol.com.br/ciencia/ultimas-noticias/reuters/2014/12/03/airbus-e-safraninauguram-joint-venture-em-lancadores-espaciais.htm?app=uol-generic\&plataforma=ipad>. Acesso em: 7 abr. 2016.
} 


\subsection{Quanto à forma jurídica adotada}

Quanto à forma jurídica adotada, a joint venture pode ser constituída pela forma societária (corporate joint venture), ou pela forma contratual (non corporate joint venture).

\subsubsection{Joint venture do tipo societário (corporate joint venture)}

Na constituição de uma joint venture, os partícipes poderão empregar as mais variadas formas societárias existentes em âmbito internacional.

No Brasil, os tipos societários normalmente utilizados são a Sociedade Limitada (Ltda.), regida pelo Código Civil de 2002, e a Sociedade por Ações (S/A), regulada pela Lei $n^{\circ}$ 6.404, de 15 de dezembro de 2006 .

O veículo mais adequado para a organização de corporate joint ventures em face da complexa disciplina das sociedades limitadas seria, na visão de Flávia Ferraz (2007, p. 29), "a sociedade anônima fechada, em que são admitidas ações ordinárias de diversas classes, com diferentes direitos políticos, fixação de quórum especial para determinadas deliberações, restrição à circulação de ações, além da previsão de execução específica de acordos de acionistas."

E quais seriam os requisitos mínimos a serem observados na constituição de uma corporate joint venture? Debruçando-se sobre a questão, Lamy Filho e Bulhões Pedreira, destacam que os partícipes deverão providenciar:

(a) Um contrato, designado acordo básico, contrato quadro, contrato de investimento ou expressões semelhantes, que funciona como instrumentomatriz no qual são definidas as condições básicas do negócio e os demais instrumentos a serem firmados; (b) $O$ estatuto social da companhia existente ou a ser constituída; (c) Um Acordo de Acionistas, que contém estipulações não reguladas pelo estatuto que confirme o objeto e as peculiaridades da joint venture; podendo incluir, ainda, contratos de fornecimento de tecnologia ou insumos de prestação de serviços, de administração ou comercialização, de empréstimos, de compra de produtos etc. (AMARAL, 2004).

Não há, contudo, impedimento para a utilização de outras modalidades societárias, mas a responsabilidade ilimitada que caracteriza as demais espécies de sociedade faz a diferença no momento de sua definição. 


\subsubsection{Joint venture contratual (non corporate joint venture)}

A non corporate joint venture ou joint venture contratual, como é conhecida no Brasil, caracteriza-se "por ser uma associação de interesses em que os riscos são compartilhados" (BASSO, 2002, p. 43), contudo não se cria uma empresa conjunta com personalidade jurídica separada daquela dos co-ventures, razão pela qual “caberá às partes definir a forma de atuação e colaboração, além de outros aspectos julgados necessários, através da celebração de um contrato, por meio do qual as partes convencionam um esquema de colaboração para que o negócio seja executado, bem como a partilha dos lucros ou prejuízos e o controle da gestão. Normalmente é desnecessária a nomeação de um corpo administrativo para controlar a execução do projeto." (AMARAL, 2004).

O emprego de joint venture do tipo contratual no Brasil ocorre por meio da constituição de consórcios, já que nos termos do art. $278, \S 1^{\circ}$, da Lei das $S / \mathrm{A}^{12}$, esse modelo empresarial não possui personalidade jurídica.

\subsection{Quanto ao risco do empreendimento}

Quanto ao risco, a joint venture pode ser classificada em equity corporate joint venture e non equity joint venture.

$\mathrm{Na}$ equity joint venture, ocorre uma associação de capitais sujeitando os coventures aos riscos do empreendimento. Por meio dessa modalidade "muito comum na Ásia, na América Latina, na África e na Europa Oriental” (BASSO, 2002, p. 43), o investimento direto de capitais em empresas estrangeiras pode ocorrer "através de subscrições de participações acionárias em sociedades nascentes de outros países, ou então por meio da aquisição de participações em sociedades" (PEREIRA NETO, 1995, p. 53).

\footnotetext{
${ }^{12}$ Art. 278. As companhias e quaisquer outras sociedades, sob o mesmo controle ou não, podem constituir consórcio para executar determinado empreendimento, observado o disposto neste Capítulo.§ $1^{\circ} \mathrm{O}$ consórcio não tem personalidade jurídica e as consorciadas somente se obrigam nas condições previstas no respectivo contrato, respondendo cada uma por suas obrigações, sem presunção de solidariedade.
} 
$\mathrm{Na}$ non equity joint venture, por outro lado, em vez da contribuição mútua de capitais, as empresas promovem uma troca de know-how visando aperfeiçoar e desenvolver a sociedade empresarial.

\subsection{Quanto à duração}

Quanto à duração, as joint ventures podem ser classificadas como transitórias e permanentes, quer sejam societárias (corporate) ou contratuais (non corporate).

\subsubsection{Joint ventures transitórias}

A joint venture transitória tem como escopo a realização de um negócio específico, razão por que após a sua conclusão a associação é desfeita.

Segundo Patrícia Carvalho (2004), "existem casos de joint ventures temporárias que acabaram se desenvolvendo para uma cooperação de continuidade, ou mesmo de parceiros que utilizaram a temporária para se conhecerem melhor, firmando, a posteriori, uma parceria sem limites temporais."

Nessa modalidade, destacam-se a sociedade em conta de participação e o consórcio.

\subsubsection{Consórcios}

Este modelo é disciplinado pela Lei $n^{\circ} 6.404 / 76$ (art. 278 e 279) e representa uma união de sociedades para a realização de um empreendimento determinado, tal como a participação em licitações e obras de grande porte, que exigem esforço conjunto de diferentes empresas.

Apesar de estar previsto na Lei das S/A, será constituído mediante contrato e poderá ser operacionalizado por tipos societários diferentes.

O art. $278, \S 1^{\circ}$ da Lei das Sociedades por Ações é expresso no sentido de determinar que o consórcio não possui personalidade jurídica, razão pela qual as consorciadas somente se obrigam nas condições previstas no respectivo contrato, respondendo cada uma por suas obrigações, sem presunção de solidariedade.

O consórcio se encaixa na modalidade de joint venture provisória porque "não é de sua natureza ser permanente; pelo contrário, o consórcio é uma associação 
temporária, podendo o contrato correspondente fixar um prazo para sua extinção." (FERRAZ, p. 37).

Não se pode olvidar que nos termos do art. 90, IV, da lei nำ12.529, de 30 de novembro de 2011, os consórcios ou joint ventures que ensejem atos de concentração deverão ser submetidos aos ditames da Resolução nํㅜ 2, de 29 de maio de 2012, estabelecida pelo Conselho Administrativo de Direito Econômico (CADE), que disciplina a notificação dos atos de que trata o art. 88 da Lei no 12.529 , de 30 de novembro de 2011, prevendo procedimento sumário de análise de atos de concentração e estabelecendo outras providências.

\subsubsection{Sociedades em conta de participação}

Embora receba o nome de "sociedade", a "sociedade em conta de participação" não é uma "sociedade" típica. Trata-se, na verdade, de uma sociedade não personificada, pela qual a atividade constitutiva do objeto social é exercida unicamente pelo sócio ostensivo, em seu nome individual e sob sua própria e exclusiva responsabilidade, participando os demais dos resultados correspondentes (art. 991 do Código Civil).

As características que a afastam esse modelo societário da sociedade empresária típica, são a despersonalização - por isso não assume nenhuma obrigação em seu nome - e a natureza secreta.

A sociedade em conta de participação é, além de despersonalizada,
também secreta, ou seja, o contrato entre os sócios, que deu início à
conjugação de esforços no desenvolvimento de empresa comum,
não pode ser registrado no Registro das empresas. Se os credores
do sócio ostensivo têm conhecimento da existência da sociedade em
conta de participação, não haverá quebra do seu caráter secreto,
posto que este reside não no desconhecimento que o meio
empresarial tenha da associação, mas, sim, na proibição do registro
na Junta Comercial. Nada impede, por conseguinte, o registro do ato
constitutivo da sociedade em conta de participação no Registro de
Títulos e Documentos, para melhor resguardo dos interesses dos
contratantes. Destaca a lei que este ato registrário não confere à C/P
personalidade jurídica. (COELHO, 2005, p. 151).

Os casos mais comuns de aplicação de joint venture por meio da sociedade em conta de participação envolvem construtoras que se valem dos chamados 
"investidores" para o financiamento da obra. Com o fim da construção, a sociedade será desfeita.

\subsection{2 joint ventures permanentes}

A joint venture permanente não estipula um prazo de duração para a associação empresarial. Um bom exemplo para essa modalidade é filial comum internacional, já que por meio dela duas ou mais empresas independentes constituem com seus capitais uma filial comum, a qual é administrada em conjunto pelas parceiras, escolhendo uma das formas societárias em direito admitidas para o seu legal funcionamento no país hospedeiro (CARVALHO, 2004).

Segundo Maristela Basso, o jurista italiano Piero Pennetta (1998, p. 10; 41 apud BASSO, 2002, p. 52) dedicou ao tema um dos mais bem elaborados trabalhos que podemos encontrar. De acordo com o referido autor "a filial comum é uma sociedade cujo capital é detido por duas ou mais empresas independentes (chamadas empresas-mães) e cuja direção econômica é exercida por elas conjuntamente, qualquer que seja o quantum das suas participações no capital social"; "na filial comum o controle estável é exercido conjuntamente por duas ou mais empresas independentes, às vezes concorrentes em outros setores econômicos e geográficos, e cuja cooperação pode, algumas vezes, também ser limitada no curso do tempo."

\section{CONCLUSÃO}

O contrato de joint venture, original do direito anglo-saxão, constitui uma forma de investimento estrangeiro direto que possibilita o desenvolvimento de projetos específicos, através da cooperação empresarial.

Em razão da ausência de definição legal, os seus elementos caracterizadores foram construídos inicialmente pela jurisprudência norte-americana permitindo que o instituto se espalhasse de forma quase universal.

A flexibilidade desse mecanismo de cooperação empresarial possibilita que os partícipes possam se valer ou não de uma forma societária; apresentar motivações diferentes (enquanto uma empresa visa o lucro, a outra pode estar simplesmente em busca de novas tecnologias - know-how), mas, sobretudo, tem se 
revelado uma alternativa interessante à burocracia estatal brasileira, proporcionando uma redução nos custos e riscos das empresas ${ }^{13}$, além de gerar uma facilitação na distribuição e na comercialização dos bens de produção.

\section{REFERÊNCIA BIBLIOGRÁFICA}

AIRBUS e Safran inauguram joint venture em lançadores espaciais. Disponível em: <http://noticias.uol.com.br/ciencia/ultimas-noticias/reuters/2014/12/03/airbus-esafran-inauguram-joint-venture-em-lancadores-espaciais.htm?app=uolgeneric\&plataforma=ipad>. Acesso em: 13 jan. 2015.

AMARAL, Antonio Carlos Rodrigues (Coord.). Direito do Comércio Internacional: aspectos fundamentais. p. 245-268. São Paulo: Lex, 2004.

BAPTISTA, Luiz O.; DURAND-BARTHEZ, Pascal. Les associations d'enterprises (joint ventures) dans le commerce international. 24. ed., 1991.

BASSO, Maristela. Joint ventures: manual prático das associações empresariais. 3. ed. Porto Alegre: Livraria do Advogado, 2002.

CADE aprova joint venture entre Cielo e Banco do Brasil. Disponível em: <http://g1.globo.com/economia/negocios/noticia/2014/12/cade-aprova-joint-ventureentre-cielo-e-banco-do-brasil.html>. Acesso em: 9 jan. 2014.

CARVALHO, Patrícia. Joint venture: uma visão econômico-jurídica para o desenvolvimento empresarial. Curitiba: Juruá, 2004.

CASTRO, Eduardo Spinola e (Coord.). Reorganização societária. p. 124-125. São Paulo: Quartier Latin, 2005.

COELHO, Fábio Ulhoa. Manual de direito comercial. p. 151. São Paulo: Saraiva. 2005.

GARCEZ, José Maria Rossani. Curso de direito internacional privado. Rio de Janeiro: Forense, 1999. p.214.

FERRAZ, Daniel Amorin. Joint venture e contratos internacionais. p. 109. Belo Horizonte: Mandamentos, 2001.

FERRAZ, Flávia. Joint ventures internacionais: aspectos de sua formação, características e término. Dissertação de mestrado apresentada ao Departamento de Direito Internacional da USP em 2007.

\footnotetext{
13 "A joint venture, de maneira geral, será um contrato no qual duas ou mais pessoas (físicas ou jurídicas), privadas ou públicas, nacionais ou de países diversos, constituirão um acordo de cooperação, mantendo sua personalidade jurídica autônoma (e, regra geral, sua independência econômica), tendo como principal fundamento a busca de um objetivo comum. Com a elaboração do contrato de joint venture, terão as partes a possibilidade de alcançar um objetivo determinado (objetivo comum) e com o benefício de realizarem um investimento reduzido e com riscos controlados". (FERRAZ, 2001, p. 27-28).
} 
FINKELSTEIN, Cláudio. Direito internacional. p. 108. São Paulo: Atlas, 2009.

FINKELSTEIN, Maria Eugênia Reis (Coord.). Direito societário: gestão e controle. Série GV law (Fundação Getúlio Vargas - Direito FGV). p. 257-258. São Paulo: Saraiva, 2008.

GAMBARO, Carlos Maria. O contrato internacional de joint venture. Revista de Informação Legislativa do Senado Federal, Brasília, n.146, 2000.

MIRANDA, Maria Bernadete; MALUF, Clovis Antônio. O contrato de joint venture como instrumento jurídico de internacionalização das empresas. Revista Virtual Direito Brasil, v. 3, p. 1-10, 2009.

PEREIRA NETO, Mario. Joint ventures com a nova união europeia. p. 53. São Paulo: Aduaneiras, 1995.

REALE, Miguel. "Joint venture" e grupo de sociedades. Revista da Academia Brasileira de Letras Jurídicas, ano VIII, n. 5, p.131. Rio de Janeiro, $1^{\circ}$ semestre de 1994.

WOLF, Ronald Charles. Effective international joint venture management: practical legal insights for successful organization and implementation. Armonk, New York: M.E Sharpe, 2002. 